\title{
Influence of Sodium Maghnite Nanoclay on the Polyvinylidene Fluoride Crystal Transition in Composite Membranes and Its Effect on Bovine Serum Albumin Protein Extraction
}

\author{
Mustapha Chabane ${ }^{1,2^{*}}$, Chikh Melkaoui ${ }^{3}$, Benamar Dahmani ${ }^{1}$, Zoubida Boudjenane $^{1}$ \\ ${ }^{1}$ Laboratory of Research on Spectrochemistry and Structural Pharmacology, Department of Chemistry, Science Faculty, \\ University of Tlemcen, Tlemcen 13000, Algeria \\ ${ }^{2}$ Institute of Science and Technology, Department of Technology, University Center of Naama, Ctr Univ Naama, Box 66, \\ Naama 45000, Algeria \\ ${ }^{3}$ Center for Scientific and Technical Research in Physical and Chemical Analysis (CRAPC), PO Box 384 Bousmail Tipaza \\ 42004, Algeria
}

Corresponding Author Email: chabane@ cuniv-naama.dz

https://doi.org/10.18280/acsm.450301

Received: 11 March 2021

Accepted: 21 May 2021

\section{Keywords:}

crystal, PVDF, composite, membrane, PVP,

Maghnite, piezoelectric

\begin{abstract}
The crystal structure of poly (vinylidene fluoride) (PVDF) and morphology of composite membranes prepared from mixture of PVDF, Polyvinylpyrrolidone (PVP) and Sodium Maghnite nanoclay has been investigated in this research work. Several analytical methods were used for the characterisation of synthesised membrane samples such as FTIR spectroscopy, X-ray diffraction (XRD), porosity and contact angle It was found the effect of adding of increasing amounts of Maghnite can improve the piezoelectric phase of PVDF. These is confirmed by the increase of the Beta crystal phase ratio. It was proved also that the synthetised membranes occurs different interaction with Serum Albovine protein by the increase of the fouling index fluxes for the membrane with reach content of Maghnite. Which confirm that the deposition effect of BSA in the membrane surface with high amounts of $\beta$ crystal structures.
\end{abstract}

\section{INTRODUCTION}

Polyvinylidene fluoride (PVDF) is semi crystalline polymer which can be used in free or combined states for the manufacture of different materials such as sensors and porous membranes applied for ultrafiltration and microfiltration separation technology [1]. The selective choice of PVDF as favorable macromolecule for industrial applications is mainly due to his attractive properties such as the mechanical strength, chemical stability, thermal resistance and electrical conductivity. However, PVDF membrane with hydrophobic characteristic affect considerably the water permeability by causing fouling phenomenon, which represent negative effect for membrane filtration sieving mechanism. Considering this limited factor, it would be useful to make modification in PVDF membranes, this is related principally to PVDF The molecular structures of PVDF show that the macromolecule is formed by repeating unit $-\left(\mathrm{CF}_{2} \mathrm{CH}_{2}\right)^{-}$, the structural composition is the mixture combination between amorphous and crystalline phases equivalent to conformation structures (TGTG)' for $\alpha$ and $\delta$, (TTTT) for $\beta$, (T3GT3G) for $\gamma$ and $\varepsilon$. As it was represented in the Figure 1, the most imporant two phases of PVDF are $\alpha$ and $\beta$, this is related to the possibility of the use of composite materials with rich amounts $\alpha$-PVDF or $\beta$-PVDF in different industrial sectors the non-polar $\alpha$ crystalline phase is more energetical stable compared to the polar phase $\beta$, that posseces pierzolectrical or pyrelectrical properties. The PVDF composite materials with very rich amounts of $\alpha$ crystalline phase can be applied for the manufacture of membranes filtration, whereas $\beta$ phase is commonly used for the fabrication of other materials such as membrane sensors and also for the biomedical application and consequently, the predominance of $\alpha$ or $\beta$ phases can influence the physical and chemical properties of the material based on PVDF. In this context, several research studies have focused on the orientation of the PVDF polymorphism during the synthesis according to the objectives of the use of PVDF composite membranes for different activities. for example, improvement of antifouling membrane properties by increasing of the percentage of $\alpha$ crystalline phase in PVDF structure [2]. It was noted also that the conditions of synthesis play an important role in the predominance of $\alpha$ and/or $\beta$ crystal phases. In this context, Liu et al. [3] studied the effect of the membrane preparation techniques and operating conditions on the type of the crystal phases of PVDF membranes, it was found that the NIPS method promote the formation of a mixture of $\alpha$ and $\beta$ phases with a crystallinity rate of $60 \%$. However, it was observed the predominance of the $\beta$ crystalline phase when the evaporation temperature achieves $60^{\circ} \mathrm{C}$. As well, the $\alpha$ crystalline phase became more predominant where the solubility of PG increased in casting solution. Fontananova et al. [4] have studied the effect of the casting solution composition on the morphology and crystalline phases of $\mathrm{PVDF} / \mathrm{MWCNTw} / \mathrm{LiCl}$ composite membranes. The synthesis was carried out with two different experimental protocols. it was observed that the higher polymer concentration has an influence on the crystallization phenomenon of PVDF. Conversely, it was found that the application of protocol $\mathrm{B}$ relative to the low polymer concentration and hydrophilic additive $\mathrm{LiCl}$ trend to cellular structures formation. The $\beta$ polar phase of PVDF being predominant for all the synthesized membranes, while the $\alpha$ 
crystalline phase appear with the adoption of protocol A (High polymer concentration). This proves that the crystallinity of PVDF is linked to the additives interaction between neutral MWCNT and polar $\mathrm{LiCl}$, which promotes the formation of the $\beta$ phase. Moreover, it was deduced that the membrane morphologies are straightly related crystal phases, it was observed also that more hydrophilicity of membranes. PVDF composite membranes containing a high percentage of the $\beta$ phase have an affinity with respect to fouling, however the antifouling characteristic $\alpha$ crystalline phase. it has been proved that structural modification on the polymeric chains of PVDF occurred by hydrogen intermolecular band with oxygen atoms of inorganic materials [4]. During the preparation of membranes by the NIPS method, the difference of temperatures between the solvent and the non-solvent influences the crystallization phenomenon of PVDF and therefore determines the nature of the polymorphism for this purpose, the efficiency of solute separation from a solution is strongly related to the types of polymorphism of PVDF membranes. Among the important applications of the electrical properties of $\beta$ phase PVDF membranes is the monitoring of fouling by $\mathrm{AC}$ method whose principle on the measurement of the signals vibration which depends to the thickness of foulant layers deposited in the membrane, in order to choose the appropriate conditions for better cleaning of the membranes [5]. One of the most important parameters that influence the crystallization and polymorphism is the solubility of PVDF in solvent. In this context, the influence of the temperature and ultrasonication on the dissolution of PVDF in dope solution and their effect on the properties of PVDF ultrafiltration membranes have been studied by Ike et al. [6] it was observed the regular increase of $\beta$ phase ratio with temperature of PVDF dissolution. The application ultrasonication method produce dense membrane with low porosity, small size pore and smooth surface. The continuous investigations on the between transition crystal phases from $\alpha$ to $\beta$ and physical parameters were established, they have observed during the preparation and characterization of PVDF transparent films the growing of $\beta$ phase amounts at fixed solvent evaporation temperature of $60^{\circ} \mathrm{C}$ and also in the final stage by the effects of the pressure and high temperature applied for releasing PVDF films from glass support [7, 8]. The composite membrane based on PVDF and organic/inorganic additives are different. Among the selected additives CNT and nanoclay are considered an efficient inorganic compounds for the enhancement of durability, mechanical strength and antifouling properties, Lai et al. [9] have collected literature data on the performance nanofillers containing PVDF/nanoclay the investigation review show that the effect of nanoclay in the nucleation mechanism of PVDF by favors the transition to $\beta$ phase form and consequently increase the roughness, mechanical strength and abrasion resistance. Indeed, the inclusion of nanoclay into PVDF matrix structure cause physical coating. In general, the PVDF/nanoclay membrane applied as hollow fiber configuration for low pressure filtration technology PVP is one of the pore-creating agents added to the PVDF/nanoclay mixture. Little research work has evoked these inhibitory effects on the interaction of nanoparticles on the surface of the PVDF membrane [9]. The understanding of the nanoclays mechanism on the modification of the properties for nanocomposite structures PVDF-HFP was the subject of the research carried out by Atanassov et al. [10] which includes bentonite and original montmorillonite on copolymers matrix based on PVDF and HFP, the comparative results show that the addition of bentonite additive increase the $\beta$ phase amounts. The contribution of nanoclay for the preparation of composite materials with piezoelectric property was established by Sadeghi et al. [11]. The research focused on the highlight the physical characters of nanotubes of carbonne and nanoclay on the improvement of PVDF/CNT/Nanoclay composite property. The results prove the effect of nanoclay inclusion on the involve of $\beta$ crystal phase and therefore the piezoelectric activity. Dillon et al. [12] have reported the effect of modified nanoclays 'Cloisite $15 \mathrm{~A}$ and Cloiste $25 \mathrm{~A}$ ' on the properties of the PVDF/nanoclay nanocomposite. the nanomaterials have been synthesized by casting and precipitation techniques It has been found the different behavior of cloisite 15A and Cloisite $25 \mathrm{~A}$ on PVDF polymeric matrix. This was explained by the difference of intercalation and phase separation phenomenon. The DMF solvent has good ability for the extrapolation the using two different nanoclays of cloisite with different size present significative difference in crystallite sizes and crystal phases related to dominance of $\alpha$ or $\beta$ crystal phases under different conditions [13]. The additives formed by combination between nanoclays and polymeric structures has been considered as privileged way for the manufacturing PVDF blended membrane, but several questions are posed for the techniques of synthesis. In this context, research work has been realized by Schiefferdecker et al. [14] based on the comparison between electectrospining and casting methods when nanocomposite membranes PVDF/Mt-PPy. DBSA was prepared. With the same fractions of additive Mt-PPy. DBSA, it was observed that the $\beta$-PVDF crystalline phase is highly present in nanocomposite membranes prepared by electrospining method. Moreover, the application of casting method produce membrane with superior electrical conductivity values of membranes. Cai and $\mathrm{Wu}$ [15] have synthetised additive by incorporation dopamine to montmorillonite sodium nanoclay. The composite membranes were prepared via NIPS method by the inclusion of dopamine modified sodium montmorillonite (D-MMT) on the polymeric structure of PVDF. The characterisation test of membrane samples reveals the enhancement of hydropilic character and mechanical resistance which prove the important contribution of D-MMT nanoclay on the reinforcement of membrane structure and the increase of water permeability from 15 to 22 $\mathrm{L} / \mathrm{m}^{2} \mathrm{~h}$ for adding amount of D-MMT around $0.8 \%$. The methods of preparing PVDF/MMT membranes are diverse in particular co-precipitation and casting techniques are the most commonly used for the synthesis of PVDF composite membranes. Fu et al. [16] compared the two methods on the dispersion of nanolayers phenomenon, under different synthesis conditions such as casting and thermal treatment and their impact on the PVDF crystal phase changes, as it was represented in (Figure 2). The results show the performance solution casting method on the creation of $\beta$ polar crystalline phase, so it was found the $\alpha$ crystalline phase is obtained when the samples were treated thermally and therefore recrystalised thus leading to co-precipitation. The highlighted of the homogenous or heterogeneous MMT dispersion on the PVDF polymeric structures affect considerably the crystalline phase. Dhatarwal and Sengwa [17] have investigated the properties of nanocomposite membranes synthetised by casting techniques by adding small amount of $0.5 \% \mathrm{wt}$ of amorphous $\mathrm{SiO}_{2}$ to different weight ratios of PVDF/PEO. The difference on the morphonology, the crystallinity, crystal phase and electrical properties has been found. The crystal phase is 
related to the amount of PEO added. Indeed, the percentage of $\beta$ crystal phase achieve maximum value of $69.47 \%$ for the composition of the composite membrane $75 \mathrm{PVDF} / 25 \mathrm{PEO}-5$ wt $\% \mathrm{SiO}_{2}$. It was deduced that the amorphous $\mathrm{SiO}_{2}$ affect considerably the interaction between the PVDF and PEO which has an impact on diminution of crystalinity degree around $7 \%$ compared to the nanocomposite PVDF/PEO. While, the increase of PEO on the polymeric matrice reduce the $\beta$ crystal phase of PVDF, this was explained by the effect of the PEO amounts on the activation of $\beta$ phase. Moreover, the excess of PEO higher than $25 \%$ has inhibition effect on the growth of $\beta$ crystal phases. The application of $\mathrm{MgCl}_{2}$ as inorganic nanomaterials the enhancement of the structural and dielectric properties of PVDF matrix hybrid membranes have been established by Gaur and Rana [18]. The research idea is based on the incorporation of Magnesium into PVDF structure by NIPS using different weight ratios of PVDF/ $\mathrm{MgCl}_{2}, \mathrm{DMF}$ solvent and denoised water as no solvent. The results of characterization using XRD, FTIR [19]. Other research work by have been found the PVDF crystal change to higher value percentages of $\beta$ phases $80 \%, 71 \%$ and $84 \%$, this is due to inclusion of Cloisite 30B and MWCNT which increase the reinforcement of the surface [20]. It has been found by Mahato et al. [21] that the different synthetic methods have an impact on the progress of $\beta$ phase, crystallinity, and morphology of the PVDF films. It has been deduced the relation between the electrical properties and $\beta$ phase creation. Indeed, it was found that NIPS casting method improved the $\beta$ phase around $80 \%$. More of research works have studied the possibility of composite membrane synthesis from combination between polymeric structures and different nanoclays varieties additives and their effect on membranes characteristics, Among the nanoclays types, Montmorillonite, $\mathrm{Mg} F \mathrm{Fe}$ layered double hydroxide modified Montmorillonite (LDH-Mt) and Cloisite were applied as nanofillers additives for the composite membrane manufacturing Multiple reasons are behind the choice of these nanomaterials as additives such as their abundances in the environment, high surface areas, porosity, possibility of intercalation and new energy portion during mixture with polymers structures caused by the electrical charge mobility [22]. Makwana et al. [23] prepared matrix hybrid membrane based on PSF, PVP, Mt and LDH-Mt, the results showed the excellent contribution of nanoclays on the improvement of water permeability, fouling resistance and higher capacity for the separation of oil from water. Among the phylodilicate nanoclay types, montmorillonite nanoclays provided from Maghnia region (Algeria), this kind of nanoclay is called Maghnite has been widely used in the synthesis of nanomaterials for different physical and chemical uses, in particular Doufnoune et al., and Kherroub et al. [24, 25] has prepared a new nanofiller material from the intercalation of $\mathrm{Na}^{+}$Maghnite by cationic alkyl phosphonium salt and grafted with three silane coupling agents, the combination of the synthetized nanomaterial with other polymer structures give the possibility for the manufacturing new materials with high mechanical resistance. One of the important research innovations in material sciences is related to nanocomposite manufacturing concepted from the mixture between nanoclays and polymers. In particular; different morphological cases can appear; this depends to several factors such as the dispersion of nanoclays fillers in polymeric structures. The basic principle is to promote intercalation of lamellar structure of phyllosilicate by homogenous inclusion of polymer between the space layers of nanoclays. Which can contribute on the increase of the surface energy and therefore give hydrophilic properties to nanocomposite materials [26, 27]. Structural modification of polymers by incorporating new nanoclay functional groups on membrane surfaces have been investigated in last years, Montmorillonite has been used as additive for the enhancement of PES properties in respect to increase the parameters related to water permeability, thermic and mechanical resistance and pesticide removal. The water permeability has mostly affected by the weight ratios of clays in membrane, these was confirmed by the increase of the water permeability from $312 \mathrm{LMH}$ to $389 \mathrm{LMH}$; where the weight clay amount in membranes increases from $1 \%$ to $2 \%$ respectively [28]. Dispersion of cations electrical charges on the mineral clays has great effect on the electrical conductivity and consequently has an influence on the polarization. As well the use of Clay additive for the preparation. As well this property can enhance electrical properties of hybrid matrix nanomaterials [29-34]. The interaction between nanoclay particles and polymeric structure can influence on the membrane characteristics and crystallographic forms such as PVDF. The aim of this research work is to investigate the effect of modified nanoclay Maghnite on the crystal transition of PVDF and characteristic of composite membranes based on PVDF, PVP, Sodium Maghnite in the second stage the application of synthesized membranes will depend to the results of predominance one of $\alpha$ or $\beta$ crystal forms of PVDF. For this reason, experimental test on BSA separation by membranes will be established and the fouling index will be also measured.

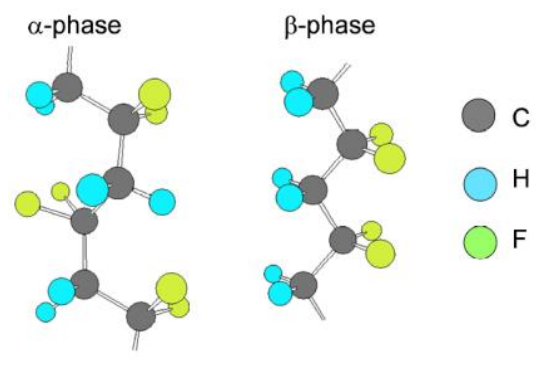

Figure 1. $\alpha$ and $\beta$ conformation structures of PVDF [4]
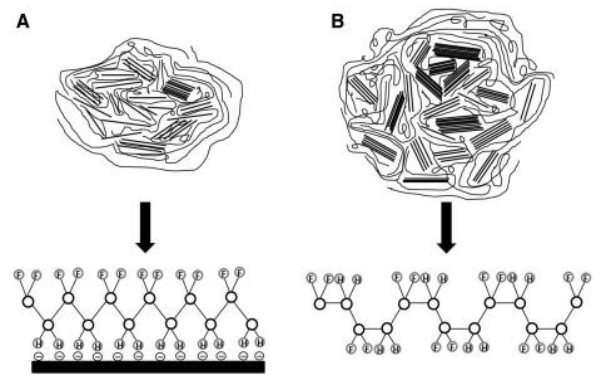

Figure 2. Descriptive scheme of the $\beta$ phase formation in systems with fine dispersion of MMT (A) and the $\alpha$ phase dispersion in systems with poor dispersion of MMT (B) [16]

\section{MATERIAL AND METHODS}

\subsection{Chemical reagents}

During the membrane synthesis stages, several chemical reagents were used, their technical data are cited in the Table 2. 


\subsection{Preparation of BSA solution}

BSA solution was prepared at a concentration of $500 \mathrm{ppm}$ at constant $\mathrm{pH}$ of 4.5 [32].

\subsection{Maghnite nanoclay treatment stages}

\subsubsection{Purification and activation of Maghnite nanoclay}

Before the purification and activation, it was The properties of natural Maghnite was establised using different methods Relative Moisture in Maghnite nanoclay.

The moisture percentage in Maghnite sample was calculated using the following equation [34]:

$$
H(\%)=\frac{\left(W_{0}-W_{1}\right)}{W_{0}} \times 100
$$

\subsection{2 $\mathrm{pH}$ measurement}

The method measurement consists on the stirring of $5 \mathrm{~g}$ of Maghnite with $100 \mathrm{ml}$ of distilled water for 5 minutes. After standing for one hour, the $\mathrm{pH}$ of the supernatant is measured using a $\mathrm{pH}$ meter $[35,36]$.

\subsubsection{Swelling index}

The method of measurement, a graduated cylinder was filled with $50 \mathrm{ml}$ of distilled water and $0.5 \mathrm{~g}$ of Maghnite was added. After 45 minutes, note the first volume V0. After 2 hours, note the volume of swelling $[37,38]$.

$$
S I(\%)=\frac{S V \times 50}{50-H(\%)}
$$

2.3.4 Weight loss fire

$$
W F(\%)=\frac{\left(W_{1}-W_{2}\right)}{W_{1}} \times 100
$$

\subsubsection{Colloidal percentage}

The colloidality was measured by the following equation:

$$
C(\%)=100 \times\left(\frac{V_{1}-V_{0}}{V_{1}}\right)
$$

where,

$V_{l}$ : Supernatant volume (L)

$V_{0}$ : volume of water added (L)

$\mathrm{H}(\%)$ : Moisture percentage

SI $(\%)$ : Swelling index percentage

$\mathrm{WF}(\%)$ : Weight loss Fire percentage

$\mathrm{C}(\%)$ : Colloidal percentage

$\mathrm{pH}$ : Potential of hydrogen

SV: Swelling volume (1)

\subsubsection{Maghnite nanoclay treatment}

Raw Maghnite must be purified from the quartz, calcite, feldspar). and the exchangeable cations of natural clay must be replaced by sodium cations. The size of maghnite particle is less than $2 \mu \mathrm{m}$ [39-42].

Sodification of maghnite. For the purification of montmorillonite, an amount of $10 \%$ is dispersed in distilled water, the mixture is stirred for 8 hours to homogenize the solution, but at the 7 th hour of stirring, $5 \%(25 \mathrm{ml}) \mathrm{d}$ A sodium chloride solution $\mathrm{NaCl}(1 \mathrm{~N})$ is added to the solution. This addition will allow rapid settling. At the end of the stirring, a colloidal solution is obtained which is poured into $2 \mathrm{~L}$ test tubes and left to stand overnight, which allows the montmorillonite sheets to swell. The solution is transferred to 2 flasks and $250 \mathrm{ml}$ of $\mathrm{NaCl}(1 \mathrm{~N})$ are added to each, then stirring is continued for 8 hours and the mixture is left to settle overnight. After decanting overnight, we notice the appearance of a supernatant liquid [43].

\subsection{Membranes synthesis method}

The composition of the synthetic solutions based on PVDF, PVP, Sodium maghnite and DMF is shown in Table 3, the components was mixed at $8 \mathrm{~h}$ with temperature of $50^{\circ} \mathrm{C}$, one uses the method of precipitation by phase inversion [1].

Table 1. Properties of $\alpha$ and $\beta$ crystalline phases of PVDF [5]

\begin{tabular}{|c|c|c|}
\hline Reagents & Commercial name & Suppliers \\
\hline \multirow{2}{*}{$\begin{array}{l}\text { Poly (vinylidene } \\
\text { fluoride) }\end{array}$} & PVDF(UdelP1700) & Sigma \\
\hline & & Aldrich \\
\hline \multirow[t]{2}{*}{ Polyvinylpyrrolidone } & PVP (K29-32) & Sigma \\
\hline & & Aldrich \\
\hline \multirow[t]{2}{*}{ Dimethylformamide } & Dimethylformamide & Sigma \\
\hline & (ACS reagent, $99.7 \%$ ) & Aldrich \\
\hline Algerian & Maghnite & ENOF \\
\hline \multicolumn{3}{|l|}{ Montmorillonite } \\
\hline $\mathrm{NaCl}$ & Sodium Chloride & $\begin{array}{l}\text { Sigma } \\
\text { Aldrich }\end{array}$ \\
\hline $\begin{array}{c}\text { Serum Albovine } \\
\text { protein }\end{array}$ & Probumin ${ }^{\circledR}$ Bovine & $\begin{array}{l}\text { Sigma- } \\
\text { Aldrich }\end{array}$ \\
\hline
\end{tabular}

\begin{tabular}{ccc}
\hline Properties & $\alpha$ & $\beta$ \\
\hline Symmetry group & P2 $1 / \mathrm{c}(\mathrm{C} 5 / 2 \mathrm{~h})$ & $\mathrm{Cm} 2 \mathrm{~m}(\mathrm{C} 14 / 2 \mathrm{v})$ \\
Structural & TGTG' & TTT \\
Conformation & & \\
Polarity & None & Strong \\
Electroactivity & None & Piezoelectric \\
& & and pyroelectric \\
Elasticity & - & Great \\
Thermal stability & - & Weak \\
Interaction with & - & Strong \\
protein & & \\
IR bands $\left(\mathrm{cm}^{-1}\right)$ & 488532615766795 & 5118401074 \\
& 85497613831423 & 127612861431 \\
XRD reflexion $\left({ }^{\circ}\right)$ & 17.718 .319 .926 .6 & 20.26 \\
\hline
\end{tabular}

Table 2. Technical and commercial data of chemical products

Table 3. Composition of casting solutions

\begin{tabular}{ccccc}
\hline Membranes & $\begin{array}{c}\text { PVDF } \\
(\boldsymbol{\%})\end{array}$ & $\begin{array}{c}\text { PVP } \\
(\boldsymbol{\%})\end{array}$ & $\begin{array}{c}\text { Sodium } \\
\text { maghnite (\%) }\end{array}$ & $\begin{array}{c}\text { DMF } \\
(\boldsymbol{\%})\end{array}$ \\
\hline M1 & 18 & 2 & 0 & 80 \\
M2 & 18 & 2 & 5 & 75 \\
M3 & 18 & 2 & 10 & 70 \\
\hline
\end{tabular}

\subsection{Characterization of membranes}

2.5.1 Fourier transformed infrared spectroscopy (FTIR) of the membrane samples

After drying the samples of each membrane at a temperature of $50^{\circ} \mathrm{C}$. The mixture of membrane samples and $\mathrm{KBR}$ pellets were prepared and analysed using The FTIR spectrophotometer (Spectrum, Perkin Elmer, USA), the spectral analyzes were carried under wave number range between 4000 to $400 \mathrm{~cm}^{-1}$. 
2.5.2 X-ray diffraction pattern analysis

The XRD diffractograms of the membranes were established using the AXS Bruker D8 model equipped with a $\mathrm{CuK} \alpha$ source $(\lambda=154 \mathrm{~nm})$. The diffraction angles $(2 \theta)$ is between $5^{\circ}$ to $90^{\circ}$ under a potential difference of $40 \mathrm{kV}$ with and a lamp current intensity of $30 \mathrm{~mA}$.

\subsubsection{Optical microscopy}

The surface of synthetised membrane samples was observed using optical microscope with resolution $40 \mathrm{X}$ referring to the method established previously [1].

\subsubsection{Porosity and mean pore size}

Membrane porosity and mean pore sizes were be calculated according to the following equations [1].

$$
\begin{gathered}
\varepsilon=\frac{\frac{\left(\omega_{\text {wet }}-\omega_{\text {dry }}\right)}{\rho_{\mathrm{w}}}}{\frac{\left(\omega_{\text {wet }}-\omega_{\text {dry }}\right)}{\rho_{\mathrm{w}}}+\frac{\omega_{\text {dry }}}{\rho_{\mathrm{w}}}} \times 100 \\
\mathrm{r}_{\mathrm{m}}=\sqrt{\frac{(2.9-1.75 \times \varepsilon) \times\left(8 \times \eta \times \varepsilon \times \mathrm{Q}_{\mathrm{w}}\right)}{\varepsilon \times \mathrm{A}_{\mathrm{m}} \times \Delta \mathrm{P}}}
\end{gathered}
$$

where, $\mathrm{w}_{\text {wet }}$ : weight of membrane $(\mathrm{g})$; $\mathrm{w}_{\text {dry }}$ : weight of membrane dried $(\mathrm{g}) ; \rho_{\mathrm{w}}$ : Density of water $\left(\mathrm{g} / \mathrm{cm}^{3}\right) ; \varepsilon$ : Porosity; $\eta$ : Water viscosity $\left(8.9 \times 10^{-4} \mathrm{~Pa} . \mathrm{s}\right) ; \mathrm{A}_{\mathrm{m}}$ : Membrane area $\left(\mathrm{m}^{2}\right)$; $\Delta \mathrm{P}$ : Difference of Pressures(Bar); $\mathrm{Q}_{\mathrm{w}}$ : Flow rate $\left(\mathrm{m}^{3} / \mathrm{h}\right) ; \mathrm{r}_{\mathrm{m}}$ : Mean pore size $(\mathrm{nm})$.

\subsubsection{Contact angle measurement}

The contact angles for membranes were established by deposition drop of distilled water on the surface of the membranes. The instrument used for these experiments is DSA model supplied by KRUSS company [15].

\subsubsection{Membrane thickness measurement}

The thickness of the different membranes was measured using a micrometer.

\subsubsection{Rejection rates of BSA and fouling index}

The water rejection rate of BSA and fouling index for each membrane was measured using pilot unit (Amicon 8200), with cell surface area is $29 \mathrm{~cm}^{2}$ used in the experimental test by Chabane et al. [1]. BSA rejection rates was calculated using the following equation:

$$
R(\%)=\left(1-\frac{\mathrm{C}_{\text {permeate }}^{B S A}}{\mathrm{C}_{\text {Feed }}^{B S A}}\right) \times 100
$$

where, $\mathrm{R}(\%)$ : Rejection rate of BSA by membranes; $\mathrm{C}_{\text {Feed }}^{B S A}$ : Concentration of BSA in feed (ppm); $\mathrm{C}_{\text {permeate }}^{B S A}$ : Concentration of BSA in permeate (ppm).

The concentration of BSA in water was determined using UV-Visible spectroscopy method. The concentration of BSA was measured at $\lambda_{\max }=278 \mathrm{~nm}$, this method has been used by Gebru and Das [44].

The fouling index was matured by the monitoring of the flux ratio indicated in the Eq. (8) [44].

$$
F I(\%)=\frac{J_{B S A P}}{J_{P W P}} \times 100
$$

where, $\mathrm{FI}(\%)$ : Fouling index; $\mathrm{J}_{\mathrm{BSAP}}$ : Permeate flux of BSA solution (LMH); $\mathrm{J}_{\mathrm{PWP}}$ : Permeate flux of pure water (LMH).

\section{RESULTS AND DISCUSSION}

\subsection{Maghnite nanoclay characterization}

The results of Maghnite nanoclay characterization are presented in the Table 4:

Table 4. Properties of maghnite nanoclay

\begin{tabular}{ccccc}
\hline $\boldsymbol{H}(\boldsymbol{\%})$ & pH & SI (\%) & WF(\%) & C(\%) \\
\hline 49.61 & 8.4 & 64.03 & 19.47 & 8 \\
\hline
\end{tabular}

According to the experimental data obtained for the maghnite clay, it was found that the swelling index is higher to $50 \%$ with important moisture content about $49.61 \%$ and low organic matter and colloidal composition. In order to improve more the properties of nanoclay, sonication method has been applied with sodium inclusion mechanism for intercalation but also exfoliation method for high dispersion of nanoclay.

\subsection{Fourier transformed infrared (FTIR) analysis}

In order to ensure the validity of the purification and activation of the maghnite, a comparative study between the IR spectra of the maghnite and the data collected from the literature. It was shown that the infrared bands of the spectrum shown in Figure 3a located at wave numbers of 3633, 3417, 1630, 1047 and $526 \mathrm{~cm}^{-1}$ correspond respectively to stretch vibration modes $-\mathrm{OH}$ of water, deformation -OH of water, symmetrical stretching $\mathrm{Si}-\mathrm{O}$, Al-O-Si deformation, and deformation of $\mathrm{OH}$ groups linked to the atoms such as aluminum and/or magnesium [41]. The mains infrared bands indicated in the Figure $3 b, 3 c$ and $3 d$ belongs to PVDF, this seems logical taking into consideration the high percentages of PVDF indicated in the Table $3.3672 \mathrm{~cm}^{-1}$ and $2898 \mathrm{~cm}^{-1}$ assigned to the $\mathrm{OH}$ stretching, and the $\mathrm{CH}$ stretch band of PVDF. The peaks at $1495 \mathrm{~cm}^{-1}$ and $1403 \mathrm{~cm}^{-1}$ represent the bending vibrations and the modes of operation of $\mathrm{CH}_{2}$, respectively. A strong band was observed assigned to the symmetrical stretch and strain modes $\mathrm{CF}_{2}$. The weak peaks between $509-485 \mathrm{~cm}^{-1}$ and $444 \mathrm{~cm}^{-1}$ were related to the waging and rocking modes of $\mathrm{CF}_{2}$. The functional groups of PVP and maghnite added to the PVDF polymer matrix are indicated in the spectra either by the appearance of new infrared bands other than that of PVDF. In particular in Figure 3b, the bands located at $1669 \mathrm{~cm}^{-1}$ is attributed to $\mathrm{C}=\mathrm{O}$ stretching vibration band of PVP; the intensity of this band must be affected with the addition of Maghnite nanoclay in the Figure $3 \mathrm{c}$ and Figure $3 \mathrm{~d}$. It was observed a change in the form of the bands under the range situated between 3200 to $2800 \mathrm{~cm}^{-1}$ for M1, M2 and M3 membrane samples, that can be explained by the creating of new bands between Hydrogen atoms of $\mathrm{CH}_{2}$ and oxygen atoms of hydroxyl group of Maghnite nanoclay, this was clearly observed by the comparison of the number of bands between $3000-2800 \mathrm{~cm}^{-1}$ for sample M2 containing $5 \%$ of Maghnite and M3 (10\% Maghnite). Moreover, same remarks have been deduced in the wave numbers region situated between 500 to $400 \mathrm{~cm}^{-1}$. 


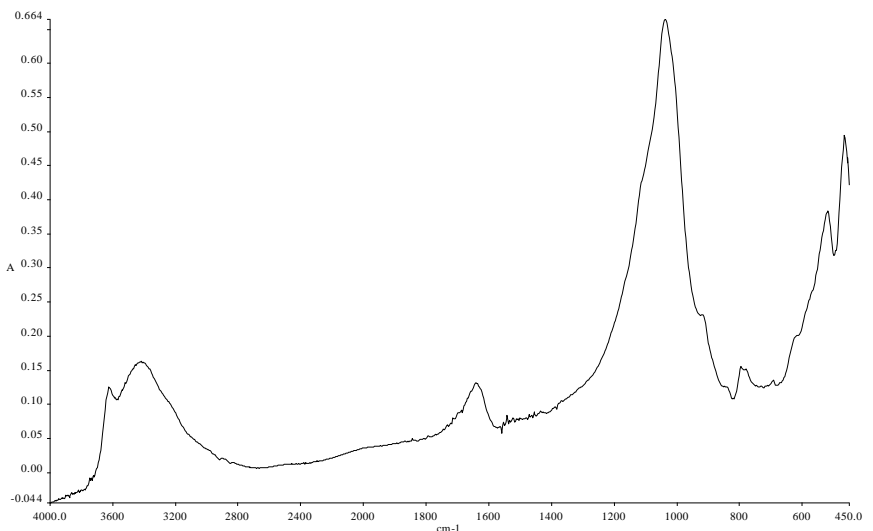

(a) purified clay $(\mathrm{Na}+\mathrm{MMT})$

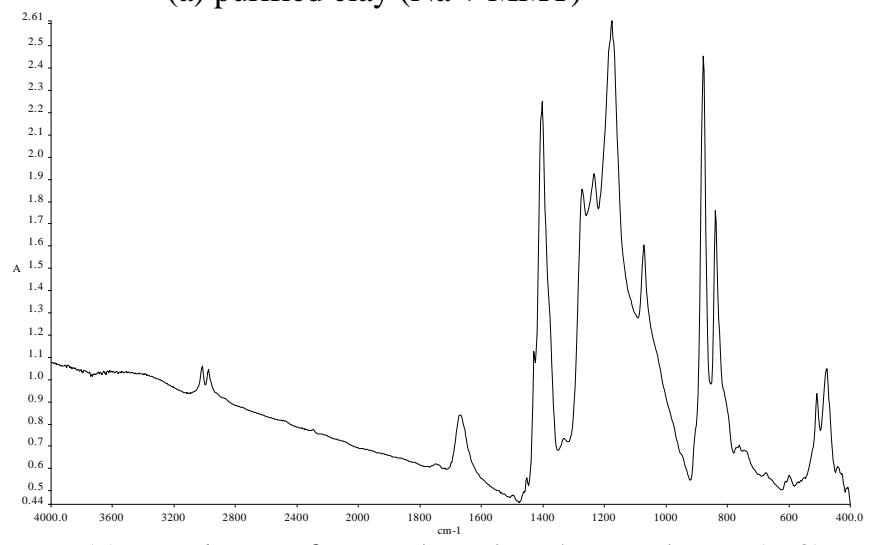

(c) Membrane of PVDF/PVP/ $\mathrm{Na}^{+} \mathrm{MMT} / \mathrm{DMF}$ (M2)

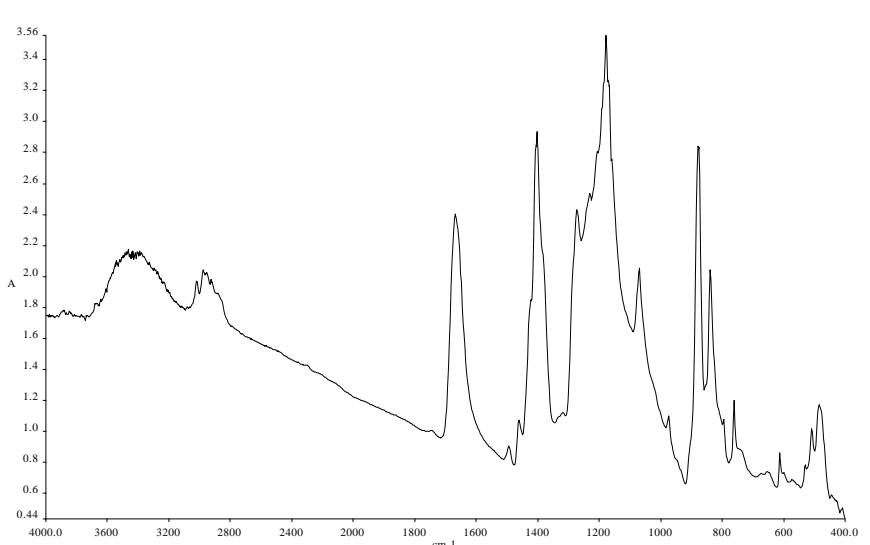

(b) Membrane of PVDF/PVP/DMF (M1)

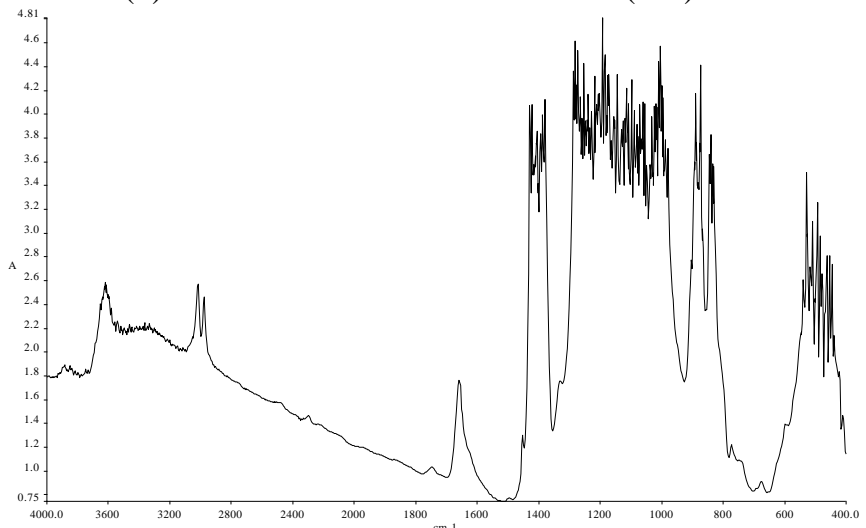

(d) Membrane of PVDF/PVP/ Na+ MMT/DMF (M3)

Figure 3. FTIR spectra of membrane samples

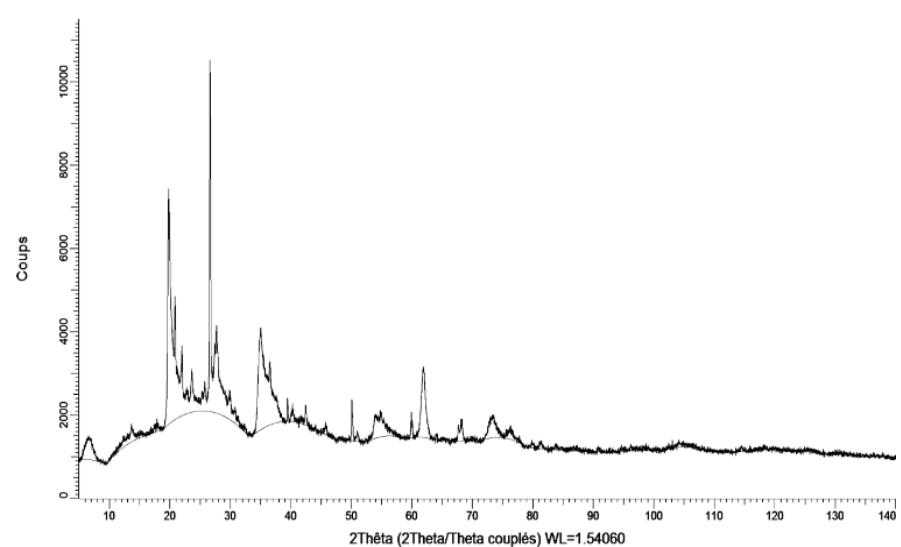

(a) Purified clay (Na+MMT)

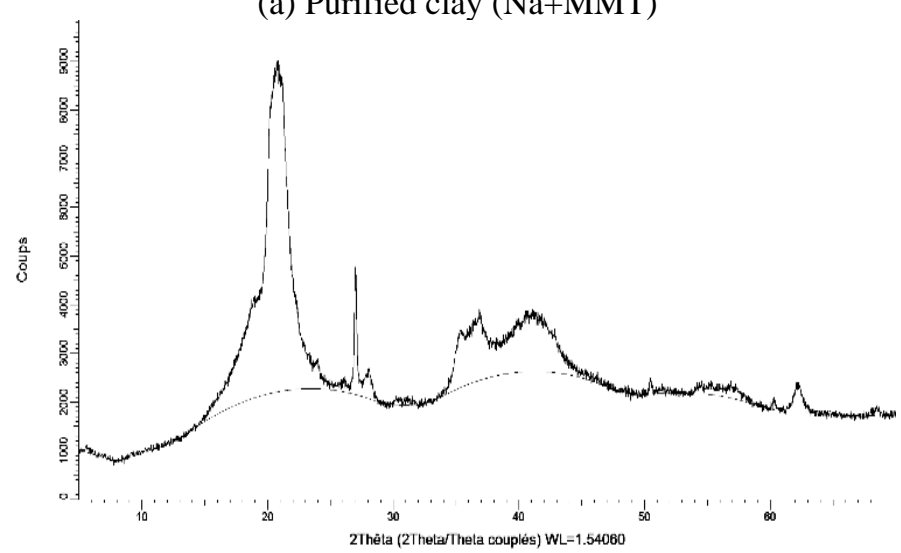

(c) Membrane of PVDF/PVP/ Na ${ }^{+}$MMT/DMF (M2)

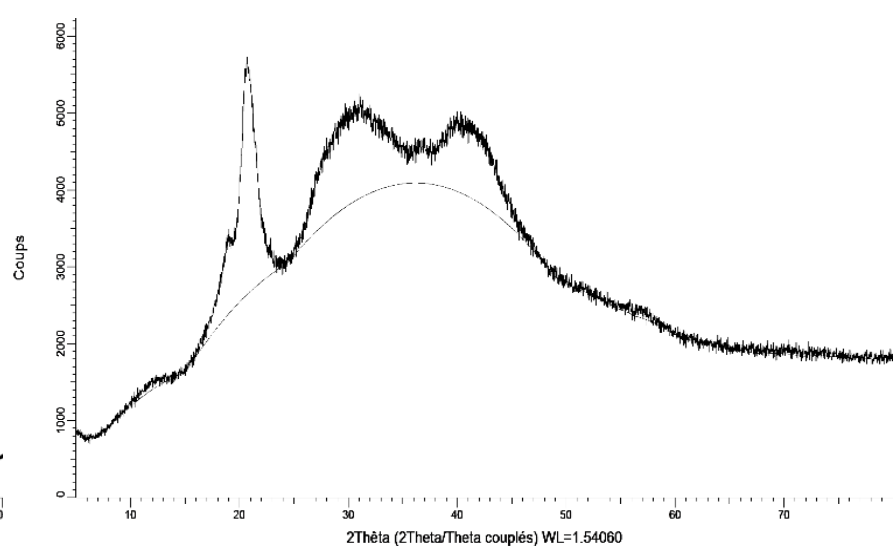

(b) Membrane of PVDF/PVP/DMF (M1)

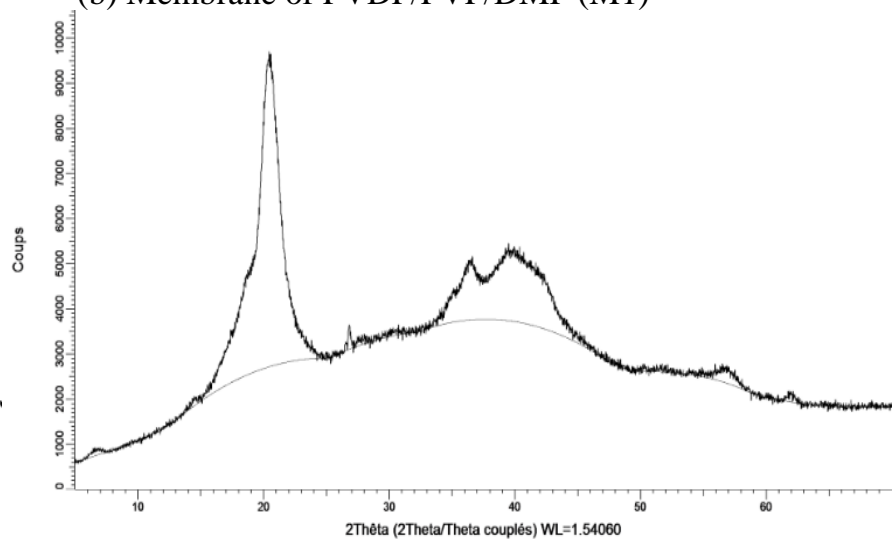

(d) Membrane of PVDF/PVP/ Na+ MMT/DMF (M3)

Figure 4. XRD analysis results of membrane samples 


\subsection{XRD patterns analysis}

According to the XRD analysis, it was observed in Figure $4 \mathrm{a}$ the presence of peak located at $2 \theta=6.9^{\circ}$ assigned to symmetry plane (001) of the sodium maghnite nanoclay, this is straightly confirmed in comparison with literature data. It was found that the peaks located at $10^{\circ}, 17^{\circ}$ and $20^{\circ}$ belongs to (001), (110) symmetrical planes respectively. The XRD data collected from Table 1 show that these planes reflect the positions of the atoms corresponding to $\alpha$ crystal conformation of the PVDF in M1 membrane [1]. The peak located at $20.26^{\circ}$ is assigned to the planes (022) of $\beta$ crystal phase of PVDF (Table 1). With the inclusion of sodium maghnite to the mixture of polymeric matrix PVDF/PVP Some changes have been occurred specially the absence of the peak located at $27^{\circ}$ in membrane M2 (Figure 4c) and M3 Figure (4d) compared to M1 (Figure 4b) with also decrease in intensity of the peak located at $40^{\circ}$.and increase of the intensity of the peak located at $20^{\circ}$ for plane (110) corresponding to $\beta$ crystal phase of PVDF for M2 and M3 membranes, Which is justified by the effect of sodium maghnite on the possibility if transition phases from $\alpha$ to $\beta$ and in the new atomic position order planes compared to the initial atomic position in the case of M1 membrane.

\subsection{Evaluation of $\beta$ crystal phase ratio factors}

The $\beta$ crystal phase amounts of PVDF on membrane samples was calculated by determination the ratio of absorbance $F(\beta)$ defined by the following equation:

$$
F(\beta)=\frac{A_{\beta}}{1.3 A_{\alpha}+A_{\beta}}
$$

where, $A_{\alpha}$ and $A_{\beta}$ correspond to absorption bands at $795 \mathrm{~cm}^{-1}$ and $840 \mathrm{~cm}^{-1}$ for $\alpha$ and $\beta$. The effect of maghnite additive in PVDF matrix on the $\beta$ crystalline phase amounts for each membrane was highlighted in this study. The Figure 5 show the increase of $\beta$ crystalline ratio from 0.54 to 0.70 with the successive increase of weight ratio of sodium maghnite under range from $0 \%, 5 \%$ to $10 \%$ for $\mathrm{M} 1, \mathrm{M} 2$ and $\mathrm{M} 3$ respectively. Indeed, with in compliance with the polymorphism data analysis obtained from FTIR and XRD and therefore it was deduced that sodium maghnite nanoclay favors the crystal phase transition of PVDF from the $\alpha$ to $\beta$ with increased polarity [45].

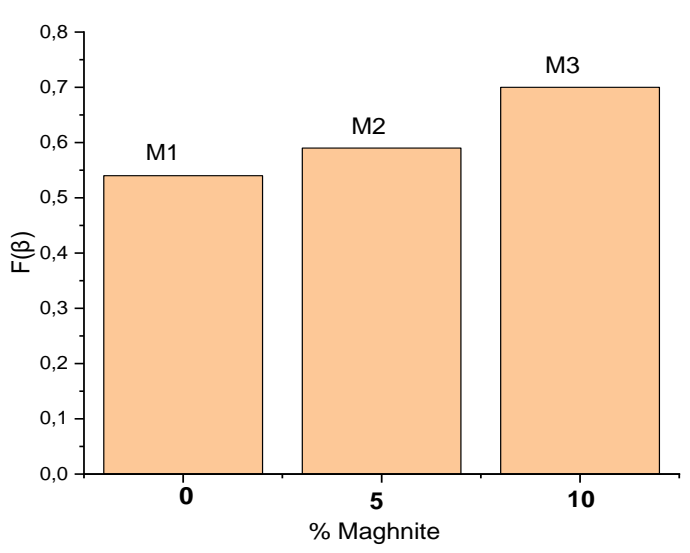

Figure 5. $\beta$ crystal phase ratios for each membrane

\subsection{Optical microscopy observation}

As it was observed in the Figure 6, it was found that by increasing of the weight ratios of the sodium maghnite in the polymeric matrix PVDF/PVP. The pore formation membrane progress. Which highlights the effect of sodium maghnite in the increase of the porosity, in order to confirm these results, additional analyzes were carried out by using, complementary tests were established in to porosity, pore size measurements and contact angle water were established.

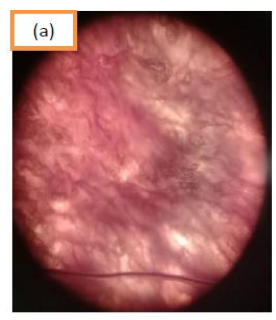

(a) M1(0\% NaMaghnite)

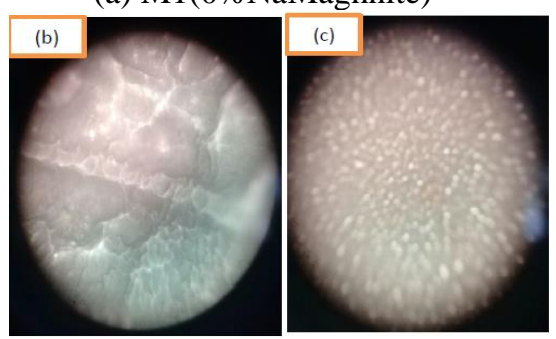

(b) M2(5\% NaMaghnite) (c) M3(10\%NaMaghnite)

Figure 6. Membrane surfaces

\subsection{Determination of membrane surface properties}

As it was shown in the Table 5, the surface properties of M1, M2 and M3 membranes indicate the influence of the sodium maghnite additive on the slight increase of the porosity, the pore size and hydrophilic character. This is justified by the effect of the inorganic bands in nanoclay composed from the mixture of Si-O and Al-O and therefore the possibility for the creation of hydrogen band with polymeric structures of the membranes and consequently the possibility to increase the number of the pores and the pore sizes Moreover, nanoclay additive increase the membrane thickness and consequently the membrane structures with rich amount of sodium maghnite became more dense structure compared to the membrane based on PVDF and PVP.

Table 5. Porosity, pore size, contact angle and thickness

\begin{tabular}{ccccc}
\hline Membranes & $\boldsymbol{\varepsilon}(\boldsymbol{\%})$ & $\mathbf{r m}_{\mathbf{m}}(\mathbf{n m})$ & $\boldsymbol{\Theta}\left({ }^{\circ}\right)$ & $\xi(\boldsymbol{\mu m})$ \\
\hline M1 & 69.25 & 67 & 95 & 88 \\
\hline M2 & 72 & 70 & 84 & 134 \\
\hline M3 & 75 & 73 & 83 & 136 \\
\hline
\end{tabular}

\subsection{Study the BSA rejection and fouling index}

According to the Figure 7, it was observed that the retention of BSA increases with the weight ratio of sodium maghnite in the composition of the membranes. This result is in conformity with the decrease fouling index expressed according to the equation. Which is explained by the deposition effect of BSA molecules leading to obstruction of the pores of the membranes. This highlights the interaction effects between 
BSA and the surface of the membranes mainly implicate the presence of the crystalline phase which interacts with the proteins such as the BSA.

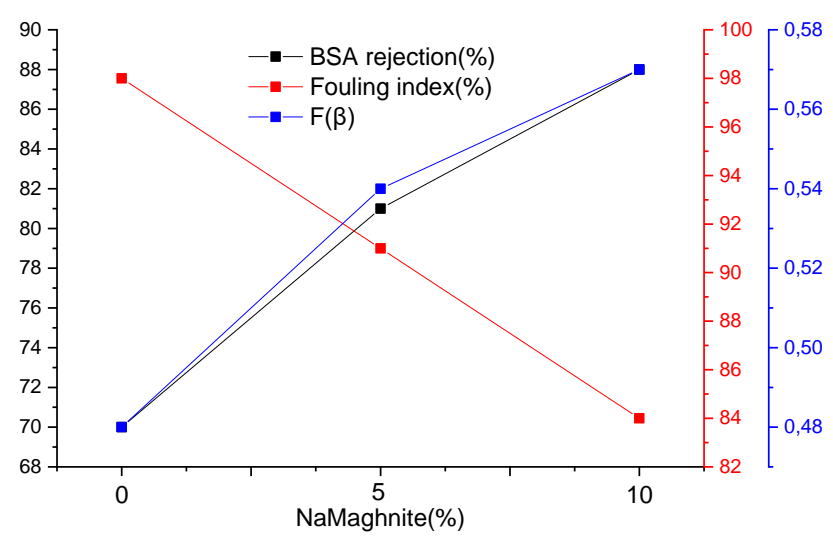

Figure 7. Effect of sodium maghnite weight ratio on BSA rejection and index fouling

\section{CONCLUSION}

The improvement of the piezoelectric properties of the composite membranes based on PVDF and PVP by the addition of sodium maghnite as an additive was highlighted during this research work. Indeed, sodium maghnite clay nanoparticles favor the crystallographic transition of PVDF from $\alpha$ and $\beta$ polar form. This is confirmed by the gradual deposition of the BSA protein on the surface of the phase-rich membranes of PVDF due to the polar attraction phenomenon and therefore it would be possible to use the membranes based on PVDF, PVP and Sodium maghnite in the separation of proteins such as BSA which represents a fairly important scientific et economical interest.

\section{REFERENCES}

[1] Chabane, M., Melkaoui, C., Dahmani, B., Belalia, S.Z. (2020). Preparation and characterization of matrix hybrid membranes polyvinylidene fluoride/polyvinylpyrrolidone/silica gel/zinc oxide for $\mathrm{Cr}(\mathrm{VI})$ removal from water. Annales de Chimie - Science des Matériaux, 44(5): 311-318. https://doi.org/10.18280/acsm.440502

[2] Jaleh, B., Gavary, N., Fakhri, P., Muensit, N., Taheri, S. (2015). Characteristics of PVDF membranes irradiated by electron beam. Membranes, 5(1): 1-10. https://doi.org/10.3390/membranes5010001

[3] Liu, J., Lu, X., Wu, C. (2013). Effect of preparation methods on crystallization behavior and tensile strength of poly (vinylidene fluoride) membranes. Membranes, 3(4): $389-405$ https://doi.org/10.3390/membranes3040389

[4] Fontananova, E., Bahattab, M.A., Aljlil, S.A., Alowairdy, M., Rinaldi, G., Vuono, D., Di Profio, G. (2015). From hydrophobic to hydrophilic polyvinylidenefluoride (PVDF) membranes by gaining new insight into material's properties. RSC Advances, 5(69): 5621956231. https://doi.org/10.1039/c5ra08388e

[5] Cui, Z., Hassankiadeh, N.T., Zhuang, Y., Drioli, E., Lee, Y.M. (2015). Crystalline polymorphism in poly (vinylidenefluoride) membranes. Progress in Polymer Science, 51: 94-126. https://doi.org/10.1016/j.progpolymsci.2015.07.007

[6] Ike, I.A., Zhang, J., Groth, A., Orbell, J.D., Duke, M. (2017). Effects of dissolution conditions on the properties of PVDF ultrafiltration membranes. Ultrasonics Sonochemistry, 39: 716726. https://doi.org/10.1016/j.ultsonch.2017.05.041

[7] Encadas, V., Gregorio Filho, R., Lanceros-Mendez, S. (2006). Processing and characterization of a novel nonporous poly(vinilidene fluoride) films in the $\beta$ phase. Journal of Non-Crystalline Solids, 352(21-22): 22262229. https://doi.org/10.1016/j.jnoncrysol.2006.02.052

[8] De Jesus Silva, A.J., Contreras, M.M., Nascimento, C.R., da Costa, M.F. (2020). Kinetics of thermal degradation and lifetime study of poly(vinylidene fluoride) (PVDF) subjected to bioethanol fuel accelerated aging. Heliyon, 6(7): e04573. https://doi.org/10.1016/j.heliyon.2020.e04573

[9] Lai, C., Groth, A., Gray, S., Duke, M. (2014). Nanocomposites for improved physical durability of porous PVDF membranes. Membranes, 4(1): 55-78. https://doi.org/10.3390/membranes4010055

[10] Atanassov, A., Kostov, G., Kiryakova, D., BorisovaKoleva, L. (2012). Properties of clay nanocomposites based on poly (vinylidene fluoride-cohexafluoropropylene). Journal of Thermoplastic Composite Materials, 27(1): 126-141. https://doi.org/10.1177/0892705712443249

[11] Sadeghi, F., Sarvi, A., Sundararaj, U. (2014). PVDF/carbonnanotubes/nanoclay composites for piezoelectric applications. International Polymer Processing, $\quad$ 29(1): 81-87. https://doi.org/10.3139/217.2814

[12] Dillon, D.R., Tenneti, K.K., Li, C.Y., Ko, F.K., Sics, I., Hsiao, B.S. (2006). On the structure and morphology of polyvinylidene fluoridenanoclay nanocomposites. Polymer, 47(5): 16781688. https://doi.org/10.1016/j.polymer.2006.01.015

[13] Kherroub, D.E., Boulaouche, T. (2020). Maghnite: Novel inorganic reinforcement for single-step synthesis of PDMS nanocomposites with improved thermal, mechanical and textural properties. Research on Chemical Intermediates, 46(12): 5199-5217. https://doi.org/10.1007/s11164-020-04257-X

[14] Schiefferdecker, V.M., Barra, G.M.O., Ramôa, S.D. A.S., Merlini, C. (2019). comparative study of the structure and properties of poly (vinylidene fluoride)/montmorillonite-polypyrrole nanocomposites prepared by electrospinning and solution casting. Frontiers in Materials, 6: 193. https://doi.org/10.3389/fmats.2019.00193

[15] Cai, Y., Wu, J. (2019). Preparation of poly (vinylidene fluoride) (PVDF)/dopamine-modified sodium montmorillonite (D-MMT) composite membrane with the enhanced permeability and the mechanical property. Desalination and Water Treatment, 141(0): 95-105.

[16] Fu, C., Wang, X., Shi, X., Ran, X. (2017). Crystalline phase of inorganic montmorillonite/poly(vinylidene fluoride) nanocomposites: influence of dispersion of nanolayers. Journal of Polymer Engineering, 37(1): 31 41. https://doi.org/10.1515/polyeng-2015-0517

[17] Dhatarwal, P., Sengwa, R.J. (2019). Impact of $\mathrm{PVDF} / \mathrm{PEO}$ blend composition on the $\beta$-phase 
crystallization and dielectric properties of silica nanoparticles incorporated polymer nanocomposites. Journal of Polymer Research, 26(8): 1-20. https://doi.org/10.1007/s10965-019-1859-5

[18] Gaur, A.M., Rana, D.S. (2016). Investigation of structural, dielectric and sensing properties of $\mathrm{MgCl}_{2} / \mathrm{PVDF}$ composite films prepared via solution casting technique. AIMS Materials Science, 3(3): 1117 1124. https://doi.org/10.3934/matersci.2016.3.1117

[19] Guo, S., Duan, X., Xie, M., Aw, K.C., Xue, Q. (2020). Composites, fabrication and application of polyvinylidene fluoride for flexible electromechanical devices: A review. Micromachines, 11(12): 1076. https://doi.org/10.3390/mi11121076

[20] Yousefi, A.A. (2011). Hybrid Polyvinylidene Fluoride/Nanoclay/ MWCNT Nanocomposites: PVDF Crystalline Transformation. Iranian Polymer Journal, 20(9).

[21] Mahato, P.K., Seal, A., Garain, S.E.N.S., Sen, S. (2015). Effect of fabrication technique on the crystalline phase and electrical properties of PVDF films. Materials Science-Poland, 33(1): 157-162. https://doi.org/10.1515/msp-2015-0020

[22] Nandi, A.K., Manna, S. (2017). Poly(vinylidene fluoride) Nanocomposites. Encyclopedia of Polymer Scienceand Technology, 143. https://doi.org/10.1002/0471440264.pst392.pub2

[23] Makwana, D., Polisetti, V., Castaño, J., Ray, P., Bajaj, H.C. (2020). Mg-Fe layered double hydroxide modified montmorillonite as hydrophilic nanofiller in polysulfonepolyvinylpyrrolidone blend ultrafiltration membranes: separation of oil-water mixture. Applied ClayScience, 192: 105636. https://doi.org/10.1016/j.clay.2020.105636

[24] Doufnoune, R., Riahi, F., Bouchareb, S., Ourari, A. (2019). Silanization of natural $\mathrm{Na}^{+}$-maghnite algerian clay pre-intercalated with a cationic alkylphosphonium salt. Journal of Adhesion Science and Technology, 1-19. https://doi.org/10.1080/01694243.2018.1551752

[25] Kherroub, D.E., Belbachir, M., Lamouri, S. (2014). Preparation and characterization of organophilic montmorillonite (12-maghnite) using Algerian clay. Oriental Journal of Chemistry, 30(4): 1647-51. https://doi.org/10.13005/ojc/300424

[26] Jlassi, K., Chehimi, M.M., Thomas, S. (2017). ClayPolymer Nanocomposites. Amsterdam, Elsevier Inc.

[27] Kotal, M., Bhowmick, A.K. (2015). Polymer nanocomposites from modified clays: Recent advances and challenges. Progress in Polymer Science, 51: 127 187.

https://doi.org/10.1016/j.progpolymsci.2015.10.001

[28] Buruga, K., Song, H., Shang, J., Bolan, N., Jagannathan, T.K., Kim, K.H. (2019). A review on functional polymer-clay based nanocomposite membranes for treatment of water. Journal of Hazardous Materials, 379: 120584. https://doi.org/10.1016/j.jhazmat.2019.04.067

[29] Jawaid, M., Qaiss, A., \& Bouhfid, R. (2016). Nanoclay reinforced polymer composites. Engineering Materials. https://doi.org/10.1007/978-981-10-1953-1

[30] Sencadas, V., Gregorio Jr, R., Lanceros-Méndez, S. (2009). $\alpha$ to $\beta$ phase transformation and microestructural changes of PVDF films induced by uniaxial stretch. Journal of Macromolecular Science ${ }^{\circledR}, 48(3)$ : 514-525. https://doi.org/10.1080/00222340902837527

[31] Felix, M., Martinez, I., Romero, A., Partal, P., Guerrero,
A. (2018). Effect of $\mathrm{pH}$ and nanoclay content on the morphology and physicochemical properties of soy protein/montmorillonite nanocomposite obtained by extrusion. Composites Part B: Engineering, 140: 197-203. https://doi.org/10.1016/j.compositesb.2017.12.040

[32] Razi, F., Mulyati, S., Arahman, N. (2019). The performance of bovine serum albumin filtration by using polyethersulfone-Tetronic 304 blend Ultrafiltration Membrane. F1000Research, 8. https://doi.org/10.12688/f1000research.18740.2

[33] Hayati-Ashtiani, M., SH, J., Ghannadi, M., Nozad, A. (2010). Experimental characterizations and swelling studies of natural and activated bentonites with their commercial applications. Journal of Chemical Engineering of Japan, 44(2): 6777. https://doi.org/10.1252/jcej.10we187

[34] Ahmad, I., Hussain, M., Seo, K.S., Choa, Y.H. (2010). Synthesis and characterization of polymer-nanoclay conductive nanocomposites. Journal of Applied Polymer Science, $\quad 116(1)$ : https://doi.org/10.1002/app.31541

[35] Merah, N., Mohamed, O. (2019). Nanoclay and water uptake effects on mechanical properties of unsaturated polyester. Journal of Nanomaterials, 2019: 1-11. https://doi.org/10.1155/2019/8130419

[36] Hanson, J.L., Yesiller, N., Badawy, A.E., Mettler, R., Stine, J.S. (2016). Determination of the index properties of clay soils in the presence of nanoparticles. In GeoChicago 2016, pp. 441-450. https://doi.org/10.1061/9780784480120.045

[37] Omar, M., Shanableh, A., Al Zaylaie, M. (2016). Modification of the swelling characteristics and phosphorus retention of bentonite clay using alum. Soils and Foundations, 56(5): 861-868. https://doi.org/10.1016/j.sandf.2016.08.010

[38] Abd El Kader, M.M., El Deeb, A.S. (2020). Preparation and characterization of low-cost waterproofing sheets from NR-loaded clay. HBRC Journal, 16(1): 1-15. https://doi.org/10.1080/16874048.2019.1688073

[39] Poli, A.L., Batista, T., Schmitt, C.C., Gessner, F., Neumann, M.G. (2008). Effect of sonication on the particle size of montmorillonite clays. Journal of Colloid and Interface Science, 325(2): 386-390. https://doi.org/10.1016/j.jcis.2008.06.016

[40] Amri, N., Radji, S., Ghemati, D., Djamel, A. (2019). Studies on equilibrium swelling, dye adsorption, and dynamic shear rheology of polymer systems based on chitosan-poly (vinyl alcohol) and montmorillonite. Chemical Engineering Communications, 206(6): 716730. https://doi.org/10.1080/00986445.2018.1521391

[41] Bouaziz, I., Doufnoune, R., Haddaoui, N., Benachour, D. Baltä-Calleja, F. (2018). Effects of Maghnite nanoclay modification and compatibilation on the physical and morphologicalpropertiesof Poly (vinylchloride)/poly (ethylene-co-vinylactetate) blends. Journal of Fundamental and Applied Sciences, 11(1): 325-349. https://doi.org/10.4314/jfas.v11i1.22

[42] Abdelkader, R., Mohammed, B. (2018). Synthesis and characterization of polymeric material consisting on acrylamide catalyzed by maghnite (Algerian MMT) under microwave irradiation. In Characterizations of Some Composite Materials. https://doi.org/10.5772/intechopen.80033

[43] Mahdavinia, G.R., Massoumi, B., Jalili, K., Kiani, G. 
(2012). Effect of sodium montmorillonite nanoclay on the water absorbency and cationic dye removal of carrageenan-based nanocomposite superabsorbents. Journal of Polymer Research, 19(9): 1-13. https://doi.org/10.1007/s10965-012-9947-9

[44] Gebru, K.A., Das, C. (2017). Removal of bovine serum albumin from wastewater using fouling resistant ultrafiltration membranes based on the blends of cellulose acetate, and PVP-TiO ${ }_{2}$ nanoparticles. Journal of Environmental Management, 200: 283-294. https://doi.org/10.1016/j.jenvman.2017.05.086

[45] Wang, X.D., Shen, H.Y., Yang, L.B., Ning, W.S., Guo, B., Huang, Y.X., Maekawa, H., Shu, K.Y. (2013). Preparation and proton conductivity of a novel polymer composite membrane PVDF-CsAl $\left(\mathrm{SO}_{4}\right)_{2} \cdot 12 \mathrm{H}_{2} \mathrm{O}$. Journal of New Materials for Electrochemical Systems, 16(2): 7982. https://doi.org/10.14447/jnmes.v16i2.12

\section{NOMENCLATURE}

$A_{m} \quad$ Membrane filtration area $\left(\mathrm{m}^{2}\right)$

$A_{\alpha}$

$A_{\beta}$

$F(\beta)$

$V$

$V_{l}$

$\mathrm{V}_{0}$

$\mathrm{t}$

BSA

$\triangle \mathrm{P}$

$J_{B S A P}$

$J_{P W P}$

$R(\%)$

Absorbance of $\beta$ crystal phase

$\beta$ crystal phase ratio

Volume of the permeate (L)

Supernatant volume (L)

Volume of water added (L)

time (h)

Bovine serum Albumine

Operating pressure test $(\mathrm{Pa})$

Permeate flux of BSA solution $\left(\mathrm{L} / \mathrm{m}^{2} \mathrm{~h}\right)$

Permeate flux of water $\left(\mathrm{L} / \mathrm{m}^{2} \mathrm{~h}\right)$

Rejection ratio of BSA by membranes
$\mathrm{C}_{\text {Feed }}^{B S A}$

Concentration of BSA in feed (ppm)

$\mathrm{C}_{\text {permeat }}^{B S A}$

Concentration of BSA in permeate ( $\mathrm{ppm}$ )

FI $(\%)$

$\mathrm{pH}$

$r_{m}$

SV

W

$\mathrm{C}(\%)$

$H(\%)$

$\mathrm{SI}(\%)$

$W F(\%)$

$J_{B S A P}$

$J_{P W P}$

\section{Greek symbols}

$\varepsilon$

$\rho_{p}$

$\xi$ $\rho_{\text {water }}$

$\eta$

ater

Subscripts

PVP

PVDF

PEO

FTIR

XRD

MWCNTw

DMF

LMH
Fouling index

Potential of hydrogen

Average pore size (nm)

Sweling volume (1)

Weight (g)

Colloidal percentage

Sweling index

Weight loss fire

Permeate flux of BSA solution $\left(\mathrm{L} / \mathrm{m}^{2} \mathrm{~h}\right)$

Permeate flux of pure water $\left(\mathrm{L} / \mathrm{m}^{2} \mathrm{~h}\right)$

Porosity of the membrane (\%")

The density of the polymer $\left(\mathrm{g} / \mathrm{cm}^{3}\right)$

The density of water $\left(\mathrm{g} / \mathrm{cm}^{3}\right)$

Membrane thickness (nm)

Water viscosity $\left(8.9 \times 10^{-4}\right.$ Pa.s $)$

Poly(N-vinylpyrrolidone)

Polyvinylpyrrolidone

Polyethylene oxide

Fourier transform infrared spectroscopy

$\mathrm{X}$-ray diffraction

Multiwalled carbone nanotube

Dimethyl formaldehyde

$\mathrm{L} / \mathrm{m}^{2} \mathrm{~h}$
Moisture percentage 